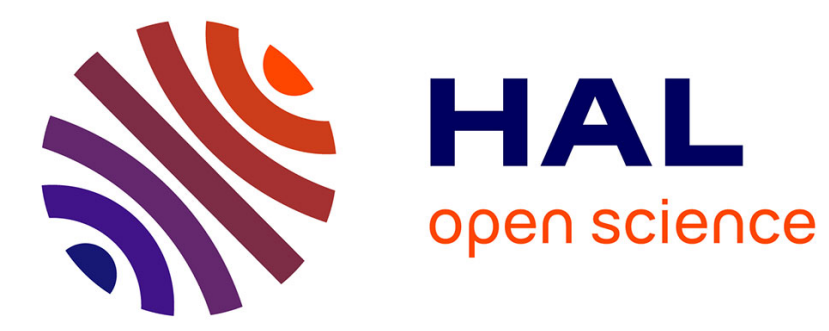

\title{
Role of the autonomic nervous system in osteoarthritis
}

Alice Courties, Jeremie Sellam, Francis Berenbaum

\section{To cite this version:}

Alice Courties, Jeremie Sellam, Francis Berenbaum. Role of the autonomic nervous system in osteoarthritis. Best Practice and Research: Clinical Rheumatology, 2017, 31 (5), pp.661-675. 10.1016/j.berh.2018.04.001 . hal-02180187

\section{HAL Id: hal-02180187 \\ https://hal.sorbonne-universite.fr/hal-02180187}

Submitted on 11 Jul 2019

HAL is a multi-disciplinary open access archive for the deposit and dissemination of scientific research documents, whether they are published or not. The documents may come from teaching and research institutions in France or abroad, or from public or private research centers.
L'archive ouverte pluridisciplinaire HAL, est destinée au dépôt et à la diffusion de documents scientifiques de niveau recherche, publiés ou non, émanant des établissements d'enseignement et de recherche français ou étrangers, des laboratoires publics ou privés. 


\title{
Role of the autonomic nervous system in osteoarthritis
}

\author{
Alice Courties ${ }^{\mathrm{a}, \mathrm{b}}$, Jérémie Sellam ${ }^{\mathrm{a}, \mathrm{b}}$, Francis Berenbaum ${ }^{\mathrm{a}, \mathrm{b}, \text { * }}$ \\ a Rheumatology Department, Saint-Antoine Hospital, Assistance Publique - Hôpitaux de Paris (AP-HP), \\ Sorbonne Universités, INSERM UMR S_938, DHU i2B, Paris, France \\ b Sorbonne Universités, UPMC Univ Paris 06, Inserm UMR S_938, DHU i2B, Saint-Antoine Service de \\ Rhumatologie, Paris, France
}

\section{Keywords:}

Osteoarthritis

Sympathetic

Parasympathetic

Autonomic nervous system innervation

\begin{abstract}
A B S T R A C T
Joint homeostasis is affected by local and systemic processes. Catecholaminergic and cholinergic fibers innervate the synovium, trabecular bone, and periosteum. Several studies have investigated the involvement of the autonomic nervous system (ANS) in joint homeostasis and the pathophysiology of osteoarthritis (OA). Various resident cells of osteoarticular tissues express receptors for sympathetic and parasympathetic neurotransmitters (norepinephrine/epinephrine and acetylcholine, respectively), which enables them to respond to autonomic stimuli. Furthermore, some of these cells are also able to synthesize neurotransmitters locally and secrete them, which may then act locally regardless of autonomic innervation. The sympathetic nervous system (SNS) is known for promoting bone loss, which has also been demonstrated in the subchondral bone during OA. However, it could interfere with other mechanisms in joint homeostasis. Indeed, intake of beta-blockers decreases pain sensation in individuals with OA; hence, the SNS could be one of the systemic links between hypertension and OA. Parasympathetic fibers may also be implicated in joint homeostasis and local control of inflammation. The vagus nerve has been found to have a strong antiinflammatory action in other rheumatic diseases through the nicotinic alpha-7 receptor, which is locally expressed by most joint
\end{abstract}

\footnotetext{
* Corresponding author. Rheumatology Department, Saint-Antoine Hospital, 184 rue du faubourg Saint-Antoine, 75012 Paris, France.

E-mail addresses: alice.courties@aphp.fr (A. Courties), jeremie.sellam@aphp.fr (J. Sellam), francis.berenbaum@aphp.fr (F. Berenbaum).
} 
resident cells. Altogether, these data suggest that the ANS is involved in joint homeostasis and OA pathogenesis.

\section{Introduction}

Osteoarthritis $(\mathrm{OA})$ is a complex multifactorial joint disease. Aging, trauma, metabolic disorders such as obesity or diabetes, and heredity are the most common risk factors [1,2]. Although OA is the most common osteoarticular disease, which affects around $10 \%$ of the population and $65 \%$ of the population after 65 years of age, its pathophysiology still remains unclear. OA involves whole-joint tissues and is mainly characterized by cartilage degradation, synovitis, subchondral bone sclerosis, and formation of osteophytes, which are under the influence of local as well as systemic factors. Pain is the cardinal symptom of OA and is partially related to joint tissue alterations. Of note, the nervous system, apparently involved in pain signaling, is also involved in these joint tissue alterations.

Sensory nerves innervate the synovium, vascularized peripheral menisci, periosteum, bone marrow, subchondral bone, and articular capsule [3-5]. They not only modulate nociceptive pain but are also involved in early skeletal development [6-9] and possibly OA pathogenesis. They imply different mediators such as calcitonin gene-related peptide or substance P, which have been reported to affect joint tissue metabolism and modulate local inflammation [10]. Sympathetic nerves also innervate the synovium [11,12] and bone [13] and may be implicated in skeletal growth [7] and OA development [14]. Conversely, very few data are available on parasympathetic innervation of the joint tissue. However, some cholinergic fibers were found in the periosteum and synovium, and these fibers could affect the inflammatory status of the joint because the vagus nerve has been found to have powerful anti-inflammatory properties by secreting acetylcholine (Ach) [15]. Furthermore, most resident cells of osteoarticular tissue have receptors for sympathetic and parasympathetic neurotransmitters and thus may respond to their stimuli. Ach and norepinephrine (NE), as major parasympathetic and sympathetic mediators, respectively, could be produced locally by non-neuronal cells and therefore affect joint tissue homeostasis regardless of autonomic innervation [12,16,17]. In addition, despite its lack of innervation, the cartilage may be affected by catecholaminergic and cholinergic mediators, produced locally in the bone or synovium, because chondrocytes express most of their receptors. During OA, sympathetic nerves were found to cross the tidemark and invade the calcified cartilage, which may alter communication between the cartilage and bone [18]. These findings strongly suggest that the ANS is involved in OA development.

This narrative review focuses on recent published data and describes the involvement of the sympathetic and parasympathetic neuronal systems and their major neurotransmitters in the pathophysiology of OA.

\section{Pathophysiology of osteoarthritis}

OA pathogenesis involves different mechanisms, depending on both the patient and the tissue involved. Aging, excess mechanical stress induced by obesity or trauma, and metabolic stress are among the most common deleterious mechanisms involved in OA. These different stresses, combined with a person's genetic susceptibility, affect the risk of developing OA.

Low-grade and sterile local inflammation occurs in OA and is characterized by an increased local production of a range of proinflammatory mediators. Cytokines (interleukins [ILs]), bioactive lipids (prostaglandin), adipokines (leptin, visfatin, and adiponectin), free fatty acids, and reactive oxygen species (ROS) are overproduced by the cartilage, synovial membrane, and subchondral bone. Synovitis is also characterized by the recruitment of innate (monocyte-macrophage) and acquired (lymphocyte) immunity cells and neoangiogenesis [19], whereas sensory nerve density seems to decrease in highly inflammatory areas of synovitis [20-22]. However, some conflicting results showed an increase in 
substance $\mathrm{P}-$ and calcitonin gene-related peptide-positive nerve fibers in the OA synovium, although the pathogenic impact of these changes is still not well understood [23]. Articular cartilage also undergoes significant cellular changes. Chondrocytes, the only cells of the cartilage, differentiate to a new stage and phenotype called hypertrophic chondrocytes. These chondrocytes are presenescent and responsible for the production of collagen $X$ instead of collagen II. They finally die by apoptosis. Furthermore, under inflammatory or mechanical stresses, chondrocytes also produce a range of cytokines, adipokines, ROS, and free fatty acids, which in turn induces the overproduction of proteolytic enzymes such as matrix metalloprotease-3 (MMP-3) and MMP-13. The process results in the release of cartilage fragments into the joint cavity, which stimulates the synovium and creates a vicious circle of inflammation. In contrast to the synovial tissue, articular cartilage is a noninnervated and nonvascularized tissue under physiological condition, but during $\mathrm{OA}$, neoangiogenesis and neurogenesis invade the calcified cartilage and the tidemark, possibly under the influence of nerve growth factor $[18,24]$. Finally, substantial remodeling of the subchondral bone occurs because of mechanical and inflammatory stresses. The remodeling even precedes cartilage lesions and is characterized by early bone loss, which increases bone remodeling followed by a slow turnover of bone, hence leading to sclerotic bone [25]. All these changes are responsible for bone cysts as well as bone sclerosis and bony outgrowths, known as osteophytes.

\section{Autonomic nervous system}

\section{Anatomy of the ANS}

The ANS is by definition independent of our will. It comprises two systems that are mainly antagonistic: the sympathetic nervous system (SNS) and the parasympathetic nervous system (PNS). These two systems have a well-defined anatomical structure and a role in a set of known bodily functions, and they mediate the neuronal regulation of internal milieu. Schematically, the SNS induces a quick response to mobilize the system, whereas the PNS induces a slowly activated dampening system. PNS functions are complex because depending on the receptor involved (alpha- or betaadrenergic), its action on organs could be different and even antagonist.

Anatomically, both SNS and PNS are two-neuron systems: a preganglionic neuron forming a first synapse with a postganglionic neuron in a vegetative ganglion and then a second synapse between the postganglionic neuron and the target organ. The SNS preganglionic neuron cell body emerges from the intermediolateral horn of the spinal cord between the first thoracic and second lumbar vertebrae. These preganglionic neurons travel through the anterior horn of the spinal cord to create a synapse with the postganglionic neuron in vegetative ganglia located in pre- or para-vertebrae. This synapse is cholinergic because the neurotransmitter is Ach, which acts on the postsynaptic nicotinic receptors. The postganglionic neuron innervates the targeted organ, where it creates an adrenergic synapse. In the adrenergic synapse, the neurotransmitter is NE and sometimes epinephrine (E), both acting on alpha- and/or beta-adrenergic receptors.

The PNS preganglionic fibers arise from two central centers. The vagus nerve, which is the major parasympathetic nerve, arises from the brain stem. The vagus nerve also contains sensorimotor fibers and has a complex anatomy. It innervates all intra-thoracic and intra-abdominal viscera because of its numerous ramifications. The second parasympathetic center, innervating the pelvic organs, is within the sacred roots. Parasympathetic ganglia are located near or in the organ innervated; therefore, the postganglionic neurons are very short. Both synapses are cholinergic. The only difference is that in the ganglia synapse, Ach acts only on nicotinic receptors, whereas in the second synapse, Ach could interplay with nicotinic or muscarinic receptors (Fig. 1).

\section{NE and Ach production and their receptors}

$\mathrm{NE}$ is the major sympathetic neuromediator. However, the SNS also involves E, neuropeptide Y, or vasoactive intestinal peptide. $\mathrm{NE}$ and $\mathrm{E}$ are both catecholamines and are synthesized from the same 


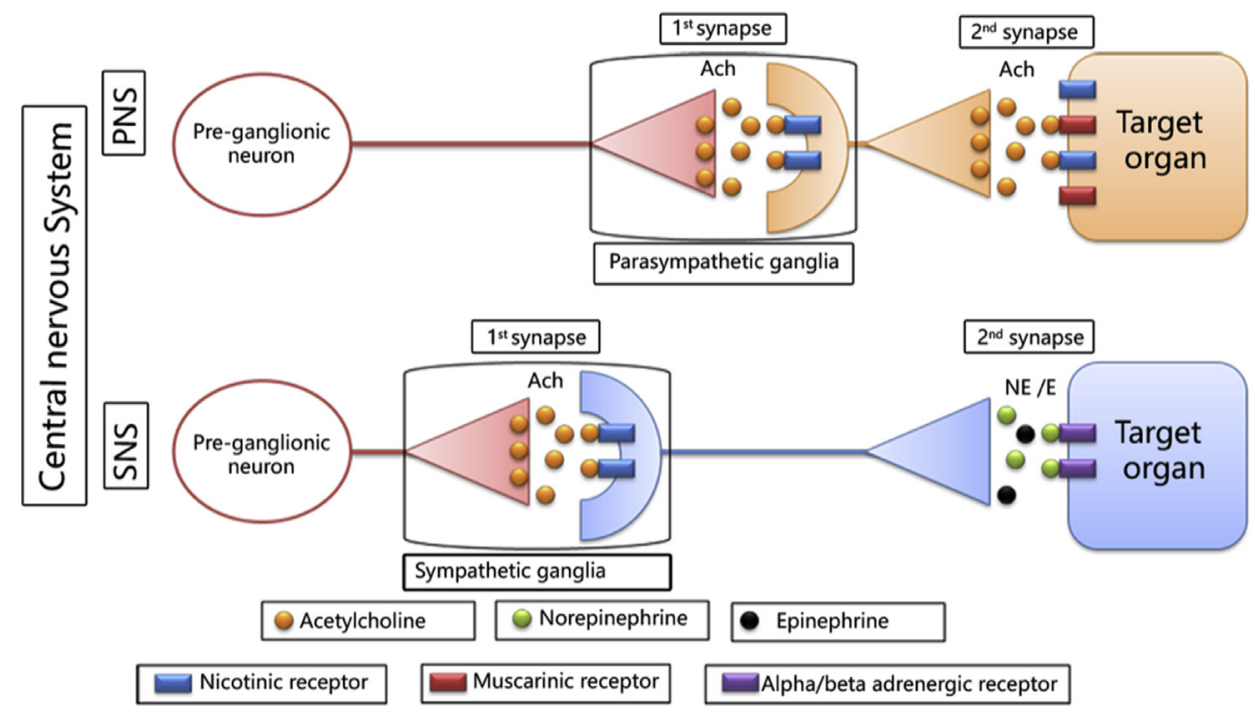

Fig. 1. Sympathetic nervous system (SNS) and parasympathetic nervous system (PNS) synapses. Preganglionic PNS neurons originate from the brainstem and sacral roots, whereas SNS neurons originate from the intermediolateral horn of the spinal cord between T1 and L2 vertebrae. The preganglionic fiber then travels to the vegetative ganglion, which is paravertebral in the SNS but very close to the organ in the PNS. The synapse within the ganglion is cholinergic because the mediator is acetylcholine (Ach). In the SNS, it interacts with the nicotinic receptor in the ganglia. Within the PNS, the postganglionic synapse with the organ is also cholinergic; the mediator is Ach. However, Ach acts on nicotinic and muscarinic receptors. In the SNS, the second synapse, which is between the postganglionic fiber and the organ, is catecholaminergic. The released neurotransmitters are norepinephrine (NE) or epinephrine (E), which act on alpha- or beta-adrenergic receptors.

precursor, phenylalanine. The limiting enzyme is tyrosine hydroxylase, which converts tyrosine to L3,4-dihydroxyphenylalanine (L-DOPA). L-DOPA is then transformed to DOPA by DOPA decarboxylase and to $\mathrm{NE}$ by dopamine $\beta$-monooxygenase. Finally, $\mathrm{E}$ is obtained from the final transformation of $\mathrm{NE}$ under the action of phenylethanolamine $N$-methyltransferase. Degradation of NE is catalyzed by monoamine oxidase enzymes. Both NE and E act on alpha (alpha-1 and -2) or beta (beta-1, -2 , or -3 ) adrenergic receptors, which activate or inhibit $G$ protein-coupled receptors.

Ach production depends on a set of proteins: choline acetyltransferase (ChAT), which acts on acetylCoA resulting from glycolysis, and choline, which mainly comes from diet. Once produced, Ach is stored in vesicles and sent to the membrane through the vesicular Ach transporter (VAchT) and released by exocytosis to the membrane. Once released, Ach can bind to nicotinic or muscarinic receptors. The nicotinic receptors belong to the ligand-gated ion channels and are formed by five subunits that may be identical (homopentamer) or different (heteropentamer) among the alpha- 2 to $-7,-9$, and -10 as well as beta- 2 to -4 subunits. Approximately 17 pentamers have been described; the most frequently expressed are homopentamer alpha-7 ( $\alpha 7)$ and heteropentamer alpha4beta2 ( $\alpha 4 \beta 2$ ). The muscarinic receptors are $G$ protein-coupled receptors. Five muscarinic receptors have been described. After binding to its receptor, Ach is degraded very quickly by acetylcholine esterase, thereby releasing acetic acid and choline. Choline is recaptured by presynaptic cells through choline transporters, which is a limiting step because choline is required for Ach production.

\section{Vagus nerve and inflammation}

In addition to its role in blood pressure, heart rate, and digestion, the ANS also has systemic action, mainly on both metabolism and inflammation. In the 2000s, Tracey et al. demonstrated that the vagus nerve has systemic anti-inflammatory action in severe sepsis. In this model, vagus nerve stimulation reduces mortality and decreases systemic tumor necrosis factor (TNF) production, whereas vagotomy 
has the opposite effect [15]. Further, stimulation of the vagus nerve was found to attenuate systemic inflammation in rheumatoid arthritis (RA) or inflammatory bowel diseases [26-29]. An understanding of the mechanisms involved has taken many years and is not yet fully understood. What is currently described is an indirect mechanism between the vagus nerve and inflammatory cells: Ach released by the vagus nerve activates the sympathetic splenic nerve in the coeliac ganglia, which releases NE locally [30-32]. NE acts on the B2-adrenergic receptors of splenic lymphocytes and induces nonneuronal production of Ach by these lymphocytes. The produced Ach binds to a nicotinic receptor called $\alpha-7$ nicotinic receptor, which is expressed by splenic macrophages. The activation of this nicotinic receptor, composed of five alpha-7 subunits, inhibits the macrophage production of cytokines mainly through the JAK2-STAT3 activation pathway and the nuclear factor kappa-B (NF- $\mathrm{BB}$ ) inhibition pathway $[33,34]$. In addition, the vagus nerve contains mostly afferent fibers connected to the central nervous system and responding to cytokines such as IL-1. These afferent fibers act on the nucleus tractus solitarius, which sends projections to the corticotrophin-releasing factor to induce adrenocorticotropin release and thus the release of cortisol, which has an anti-inflammatory effect. This is known as the hypothalamo-pituitary axis which participate to the cholinergic anti-inflammatory pathway. Furthermore, sensory and vagus nerve afferences activate the SNS.

\section{Clinical and paraclinical evaluation of the ANS}

Before the study of vagus nerve stimulation, the SNS-PNS balance could be studied at the patient level. Individuals with RA or inflammatory bowel diseases have a higher SNS-to-PNS ratio, possibly due to the loss of vagus tone, as compared with nondisease individuals. The evaluation of the ANS state is easily recorded by cardiovascular reflexes. Indeed, many tests are available and include the Valsalva maneuver, deep breathing test, isometric handgrip test, cold pressor test, and head-up tilt test [35]. The most common test used in clinical practice is the analysis of heart rate variability by extended electrocardiography. Paraclinical tests such as the measurement of the level of NE or its precursors, microneurography, or the sudomotor test could also help to determine the SNS-to-PNS ratio. Possible biases that could interfere in these measurements include tobacco use, history of hypertension, or antihypertensive drug use (alpha- and beta-blockers, anticholinergic drugs). Patients with RA show decreased heart rate variability as compared with nondisease individuals, which indicates a decrease in vagal activity [36,37]. This finding has also been demonstrated in noninflammatory diseases such as fibromyalgia or a low-grade inflammation state such as obesity. However, no study has investigated the SNS-PNS imbalance in OA, which would be of interest to determine the involvement of the ANS in the pathophysiology of $\mathrm{OA}$ and its symptoms.

\section{Autonomic innervation of normal and osteoarthritic joint tissues}

Apart from a systemic indirect effect on the regulation of vascular tone or systemic inflammation, neuromediators in the ANS may have a direct local role in joint tissue homeostasis because of the local presence of nerve fibers. Sympathetic innervation of the joint tissues and particularly the synovial membrane has been reported [11,12]. Indeed, the production of adrenergic precursors requires the expression of the limiting enzyme tyrosine hydroxylase (TH). Several authors have reported the presence of nerve fibers positive for $\mathrm{TH} /$ catecholaminergic fibers in the synovial membrane of patients with OA. The density of the sympathetic fibers in the OA synovium seems to vary little or not at all as compared with control individuals, but it was decreased in the RA synovium [12,38]. However, in highly inflammatory areas of the osteoarthritic synovial membrane, the density of nociceptive and sympathetic nerve fibers decreases [11]. Sympathetic innervation of the bone tissue has also been extensively studied. Many TH+ fibers are present in the periosteum, bone marrow, and mineralized bone [13,39-42]. TH + fibers have been detected in the subchondral bone plate of the temporomandibular joint [43]. In addition, sympathetic innervation of the infrapatellar fat pad (Hoffa tissue), a local source of inflammatory mediators, has been shown [44]. Finally, the nerve fibers that invade the deep layer of osteoarthritic cartilage during OA are sympathetic nerve fibers expressing the neuropeptide $Y$ [18]. However, neuropeptide $Y$ is not a specific marker of sympathetic fiber and is also expressed by parasympathetic and nociceptive nerves (Table 1 ). 
Table 1

Sympathetic nervous system involvement in the joint tissue and osteoarthritis.

\begin{tabular}{|c|c|c|}
\hline Topic of study & Observations & References \\
\hline $\begin{array}{l}\text { Sympathetic fiber } \\
\text { innervation of the } \\
\text { joint tissue }\end{array}$ & $\begin{array}{l}\text { - Human, rat, and sheep synovium } \\
\text { - Rat bone marrow mineralized, and periosteum and } \\
\text { mouse bone marrow and rat subchondral bone } \\
\text { - Human bone marrow, trabecular bone, and } \\
\text { periosteum } \\
\text { - Human infrapatellar fat pad } \\
\text { - Human calcified cartilage during OA }\end{array}$ & $\begin{array}{l}\text { Miller et al. (2000) [12] Eitner et al. (2013) } \\
\text { [11] Miller et al. (2004) [38] Jenei-Lanzl } \\
\text { et al. (2014) [57] } \\
\text { Mach DB et al. (2002) [13] Artico et al. } \\
\text { (2002) [40] Tabarowski et al. (1996) [39] } \\
\text { Jiao et al. (2015) [43] } \\
\text { Beckmann et al. (2013) [41], Koeck } \\
\text { et al.(2009) [42], Jenei-Lanzl et al. (2014) } \\
\text { [57] } \\
\text { Lehner et al. (2014) [44] } \\
\text { Suri et al. (2007) [18] }\end{array}$ \\
\hline $\begin{array}{l}\text { Effect of sympathetic } \\
\text { neurotransmitters on } \\
\text { the cartilage }\end{array}$ & $\begin{array}{l}\text { - Anti-inflammatory effect of NE through beta-2 } \\
\text { adrenergic receptor on human chondrocytes and } \\
\text { proapoptotic effect through alpha-1 adrenergic } \\
\text { receptor } \\
\text { - Inhibition of chondrogenic differentiation of human } \\
\text { mesenchymal stem cells, increased hypertrophic } \\
\text { markers } \\
\text { - Inhibits hypertrophic differentiation of murine } \\
\text { chondrocytes } \\
\text { - No structural effect of beta-2 adrenergic agonist } \\
\text { in vivo in a mechanical OA model } \\
\text { - Alpha-2A adrenergic receptor stimulates in vitro and } \\
\text { in vivo production of MMP-3, MMP-13, and RANK-L } \\
\text { by chondrocytes and promotes cartilage and } \\
\text { subchondral OA features }\end{array}$ & $\begin{array}{l}\text { Lorenz et al. (2015) [14] } \\
\text { Jenei-Lanzl et al. (2014) [57] } \\
\text { Lai et al. (2008) [62] } \\
\text { Tonge DP et al. (2010) [63] } \\
\text { Jiao et al. (2016) [64] } \\
\text {. }\end{array}$ \\
\hline $\begin{array}{l}\text { Effect of sympathetic } \\
\text { neurotransmitters on } \\
\text { the bone }\end{array}$ & $\begin{array}{l}\text { - Stimulation of bone resorption through beta-2 } \\
\text { adrenergic receptor } \\
\text { - Involvement in the bone physiological mechanoa- } \\
\text { daptive response through beta-adrenergic receptor } \\
\text { - Stimulate subchondral bone loss through beta- } 2 \text {. } \\
\text { adrenergic receptor, thus inducing RANK-L } \\
\text { production by bone-marrow mesenchymal stem } \\
\text { cells }\end{array}$ & $\begin{array}{l}\text { Arai et al. (2003) [67], Elefteriou et al. } \\
\text { (2005) [65], Aitken et al. (2009) [66] } \\
\text { Sseur et al. (2003) [68], Kondo et al. (2005) } \\
\text { [69] } \\
\text { Jiao et al. (2015) [43] }\end{array}$ \\
\hline $\begin{array}{l}\text { Effect of sympathetic } \\
\text { neurotransmitters on } \\
\text { the synovium }\end{array}$ & $\begin{array}{l}\text { - Proinflammatory effect of NE on human FLS } \\
\text { - Anti-inflammatory effect of NE on human FLS }\end{array}$ & $\begin{array}{l}\text { Raap et al. (2000) [60] } \\
\text { Miller LE et al. (2002) [59] }\end{array}$ \\
\hline
\end{tabular}

AbbreviationsOA: osteoarthritis; NE: norepinephrine; MMP: matrix metalloproteinase; RANK-L: receptor activator of nuclear factor kappa-B ligand; FLS: fibroblast-like synoviocytes.

Parasympathetic innervation of joint tissues has been studied less than its sympathetic counterpart. Many authors rule on the absence of parasympathetic innervation, but no negative study has been published. Furthermore, most tissues in the body innervated by the SNS are also innervated by the PNS. Two markers are used to address the presence of parasympathetic fibers: ChAT, which synthesizes Ach, and VAchT, which is responsible for the exocytosis of Ach to the membrane. Demonstrating true parasympathetic innervation is more complicated because Ach is also a mediator of the SNS, and therefore, the presence of ChAT is less specific compared to that of TH. Indeed, cholinergic fibers innervate the periosteum of rats. However, these fibers are not true parasympathetic fibers because they did not arise from the PNS but rather from sympathetic fibers that modified their phenotype during development [45]. Similarly, in mice with induced arthritis, the number of cholinergic fibers in joint tissues is higher than that of catecholaminergic fibers. However, this increase was mainly related to the presence of fibers in healthy soft tissue such as the muscle and skin. In humans, the number of cholinergic fibers is higher in the OA than in the RA synovium. The transition of cholinergic fibers from catecholaminergic fibers is thought to be related to the production of leukemia inhibitory factor by osteoclasts [43]. The presence of so-called cholinergic fibers in the synovium would therefore arise from sympathetic and not parasympathetic centers. 
Bajayo et al. successfully demonstrated parasympathetic innervation of the bone by using a labeled neurogenic pseudorabies virus injected into the metaphyseal region of a rat femur to label the parasympathetic sacral centers [47]. Other studies, using more modern methods, should be performed to answer this fundamental anatomical question because anti-inflammatory control is modulated by the PNS. Finally, the cholinergic system seems to overtake sympathetic or parasympathetic innervation because many studies now focus on the intrinsic role of Ach that can be produced outside of any neurogenic context and act locally on the receptors expressed by organs (see section E).

\section{Sympathetic nervous system and osteoarthritis}

\section{Imbalance of SNS in OA}

In 1966, Lily published the case of a patient who underwent sympathectomy for a vasospastic syndrome with ischemia of the left hand. Several years after sympathectomy, the patient showed severe right-hand OA but no left-hand OA [48]. It seems that the sympathectomy protected against OA. Since then, no study evaluating sympathectomy in OA models has been reported, but the treatment has been extensively reported in arthritis models, thus showing a delay in the initiation of arthritis [49-51]. Indeed, SNS has proinflammatory effects in the early phase of inflammation, whereas catecholamines have anti-inflammatory effects in the later phase of autoimmune arthritis. The inflammatory effect depends on the catecholamine rate and hence on the distance of the catecholamine source from the responder cell (for a complete review, see Ref. [52]).

No clinical study has described the SNS-PNS balance in patients with OA. However, hypertension seems to be associated with radiographic and symptomatic knee OA and could reflect ANS impairment [53]. Furthermore, the use of beta-blockers for OA pain was evaluated in a case-control study in 2017 involving 873 patients. Intake of beta-blockers was independently associated with less knee OA pain, less analgesic intake, and particularly less opioid use [54]. These results must be interpreted with caution because the study was cross-sectional and could not establish a causal link. The analgesic effect of beta-blockers has also been demonstrated in murine models of pain [55]. Finally, in the Osteoarthritis Initiative cohort, a prospective cohort including almost 3000 patients, alpha-blocker use was associated with less knee OA pain and less radiographic change as compared with non-use, whereas beta-blocker use was associated with only less radiographic change as compared with non-use [56].

\section{SNS and synovium}

Data on sympathetic innervation in the human synovial membrane often come from RA studies involving patients with $\mathrm{OA}$ as controls. Comparison with the healthy synovial membrane is not easy because of the sparse availability of healthy human joint tissues. Indeed, Eitner et al. studied the density of sympathetic fibers of the OA human synovial membrane and compared it to that of the normal rat and sheep synovial membranes: $\mathrm{TH}+$ fibers had decreased density within inflammatory areas of the OA synovial membrane as compared with those of controls [11]. In patients undergoing knee arthroscopy after trauma, the level of NE in the synovial fluid was found sufficient for the activation of adrenergic receptors $\left(10^{-9}\right.$ to $\left.10^{-7} \mathrm{M}\right)$. Finally, in the synovium, NE is produced by sympathetic nerves and also by synovial macrophages [12,57].

Many cells in the synovial tissue can respond to noradrenergic stimulation. Synoviocytes express most of the adrenergic receptors (including alpha-1, alpha-2A, and beta-2 receptors) [58]. The effect of $\mathrm{NE}$ on synoviocytes has been studied in vitro in RA and OA. However, the biological effect of NE is difficult to delineate because it may depend on the disease and mostly on the dose of NE used. Thus, Straub et al. first reported that NE $10^{-6}$ and $10^{-7} \mathrm{M}$ was able to increase the production of IL- 6 and IL- 8 from OA synoviocytes; 2 years later, the authors reported that $\mathrm{NE} 10^{-5} \mathrm{M}$ decreased the production of IL- 6 and TNF by OA synoviocytes $[59,60]$. The analysis is more complex because depending on the dose of NE used, some adrenergic receptors are activated and others are not. Immune cells invading the synovial membrane during OA, such as monocyte/macrophages and lymphocytes, are also able to 
respond to catecholaminergic stimulation; however, no specific studies have investigated their implication in OA pathophysiology. Finally, sympathetic activation could participate in OA pathogenesis by modulating the blood flow of synovial capillaries because the $\mathrm{TH}+$ fibers are located close to the blood vessels, but this is yet to be proven.

\section{SNS and cartilage}

In OA, neurovascular invasion of the osteochondral junction occurs by both sensory and sympathetic fibers [18]. Murine and human chondrocytes express TH and most adrenergic receptors $[14,61,62]$. Thus, whatever the stage of differentiation and the species studied, the alpha- 2 and beta- 2 adrenergic receptors are expressed by chondrocytes. The role of sympathetic mediators including NE and $\mathrm{E}$ on chondrocytes has been studied and seems to depend on the context, stage of chondrocyte differentiation, and dose used. Lorenz et al. found an anti-inflammatory effect of NE at high doses $\left(10^{-6} \mathrm{M}\right)$ on human chondrocytes through the beta-2 adrenergic receptor, whereas at a lower dose $\left(10^{-8} \mathrm{M}\right)$, NE blocked the cell cycle and had apoptotic and therefore deleterious effects through the alpha-1 receptor [14]. These results suggest a dual effect of the SNS on the cartilage. Most studies on the effect of adrenergic mediators on chondrocytes have evaluated their potential for differentiation and chondrocyte growth on their progenitors or mature cells but not on inflammation or degradation. High-dose NE inhibits chondrogenic differentiation of mesenchymal stem cells and progenitors; it decreases the production of type II collagen and glycosaminoglycans and increases the expression of hypertrophic differentiation markers such as collagen X and MMP-13 [57]. By contrast, isoproterenol, a beta-2 adrenergic agonist, inhibits the production of hypertrophic markers such as Indian hedgehog and collagen X [62]. Therefore, drawing a clear and simple conclusion is not easy. No analgesic or structural effect was observed in a mechanical OA model in rats treated with a beta- 2 adrenergic agonist [63]. The alpha-2A adrenergic receptor expression by chondrocytes increased during $\mathrm{OA}$, and its activation by NE induced the production of MMP-3, MMP-13, and RANK-ligand (RANK-L) by chondrocytes. Finally, the local injection of alpha-2A agonist in the temporomandibular joint aggravated $\mathrm{OA}$ features such as cartilage degeneration and subchondral bone loss, whereas alpha- $2 \mathrm{~A}$ antagonist treatment partially protected the OA joint [64]. Surprisingly, adrenergic receptors, especially the beta- 2 receptor, have not been studied in an OA model of knockout mice, although widely studied in osteoporosis.

\section{SNS and subchondral bone}

SNS innervates periosteum, trabecular, bone marrow, and subchondral bone and strongly affects bone tissue remodeling [7,13,39-43]. Indeed, the impact of SNS on the bone has been widely studied mainly in osteoporosis but not during OA changes and particularly not in the subchondral bone area. Since the 2000s, SNS has been considered to promote bone resorption through the beta-2 adrenergic receptor by enhancing the production of RANK-L, which stimulates osteoclasts [65-67]. SNS is also involved in regulating the bone mechanoadaptive response. Rats or mice without mechanical load on limbs have decreased bone mineral density, which is partially protected when beta-adrenergic receptors of the SNS are blocked [68,69]. Osteoclasts and osteoblasts express most of the alpha- and betaadrenergic receptors [70,71]. All these data strongly suggest that SNS could also be involved in the subchondral bone in OA, especially because mechanical stress is a strong modulator of bone remodeling in OA.

The single study published in the setting of OA is a model of experimental OA of temporomandibular joints in rats. OA was associated with a sprouting of $\mathrm{TH}+$ fibers and an increase in $\mathrm{NE}$ release and beta- 2 adrenergic receptor expression in the condylar subchondral bone as compared with controls. Furthermore, a beta-2-antagonist suppressed subchondral bone loss and osteoclast activity, whereas a beta-2-agonist exacerbated these responses; therefore, beta-2 activation through SNS stimuli mediated subchondral bone loss as in osteoporosis. This finding was due to overproduction of RANK-L by the mesenchymal stem cells of the bone [43]. 


\section{Parasympathetic nervous system, non-neuronal cholinergic system, and osteoarthritis}

\section{SNS imbalance in $O A$}

No studies have evaluated the vagal tone in patients with OA. Few data are available on the PNS in joint tissues. First, we do not even know whether PNS fibers innervate the joint tissue. However, cholinergic fibers in the bone are able to produce Ach locally, which may interact with nicotinic and muscarinic receptors locally expressed $[45,46]$.

\section{PNS and synovium}

An exciting body of research is the non-neuronal production and action of Ach: many non-neuronal cells are able to produce Ach and may express the nicotinic or muscarinic receptor, thereby allowing for a local autocrine or paracrine action of Ach. Thus, ChAT is expressed by the synovial membrane, but the cell type that secretes ChAT and whether Ach is produced because of this synovial ChAT remain unclear $[17,72]$. Synoviocytes and macrophages express a range of nicotinic subunits including alpha-7 homopentamer $[16,73,74]$. The OA synovial membrane also expresses choline transporters and muscarinic receptors $1,3,4$, and 5 and nicotinic subunits alpha- $-3,-5,-6,-7,-9$, and -10 [17,75]. Therefore, the synovium may be able to produce and respond to Ach stimulation. The specific stimulation of the alpha-7 receptor had an anti-inflammatory effect on synoviocytes of patients with RA $[74,76]$. However, no specific study on OA synoviocytes is available.

\section{PNS and cartilage}

Human chondrocytes also express some choline transporters such as choline transporter-like protein 1 to 5 and organic cation transporter 1 and 3 as well as alpha-5, alpha-7, and beta-1 (muscular) nicotinic subunits $[75,77]$. However, the production of Ach by chondrocytes has never been reported. The effect of nicotine was studied in vitro on human growth-plate chondrocytes, thus demonstrating an inhibitory effect on matrix synthesis (alkaline phosphatases and proteoglycans) and hypertrophic differentiation. This inhibitory effect is mediated by alpha-7 receptor and may explain some of the growth retardation observed in fetuses of pregnant mice with nicotine treatment [77]. Contradictory results showing that nicotine promotes the production of collagen II by human OA chondrocytes were also published, which also indicated that the nicotine effect could depend on the differentiation stage of chondrocytes [78]. Liu et al. first reported the protein expression of alpha-7 receptor by rat chondrocytes. In vivo, nicotine had a protective effect on osteoarthritic lesions induced by intra-articular injection of monoiodoacetate. Finally, using a specific antagonist in vitro, the authors showed that the anticatabolic effect observed in vivo was due at least partially to the antiinflammatory effect of alpha-7 receptor expressed by chondrocytes. Indeed, alpha-7 antagonism abolished the anti-inflammatory action of nicotine on phosphorylation of p38 extracellular signal-regulated kinase $1 / 2$ and c-Jun-N-terminal kinase mitogen-activated protein kinases as well as NF-кB p65 [79] (Fig. 2). Another study demonstrated an anti-inflammatory effect, particularly on the synovial membrane, of nicotine administered intraperitoneally in the same OA rat model. However, the small number of animals in each group in this study did not show a significant reduction in cytokine or MMP production [80]. All these studies corroborate epidemiological data supporting that tobacco use is associated with reduced knee OA [81,82], which remains controversial. However, a proinflammatory effect of nicotine was reported in human OA chondrocytes in vitro [83].

\section{PNS and bone}

The effect of the PNS on the subchondral bone remains unknown to date. However, several studies have investigated the role of the PNS in bone homeostasis and osteoporosis. Rat osteoblasts express alpha-1, -4 , and -7 as well as beta- $1,-2$, and -4 nicotinic subunits, whereas murine osteoclasts express alpha- 2 and -5 and beta-1, -2 , and -4 subunits [47]. Bajayo et al. demonstrated a positive effect of PNS on bone mass. The application of cholinergic agonists to osteoclasts increased 


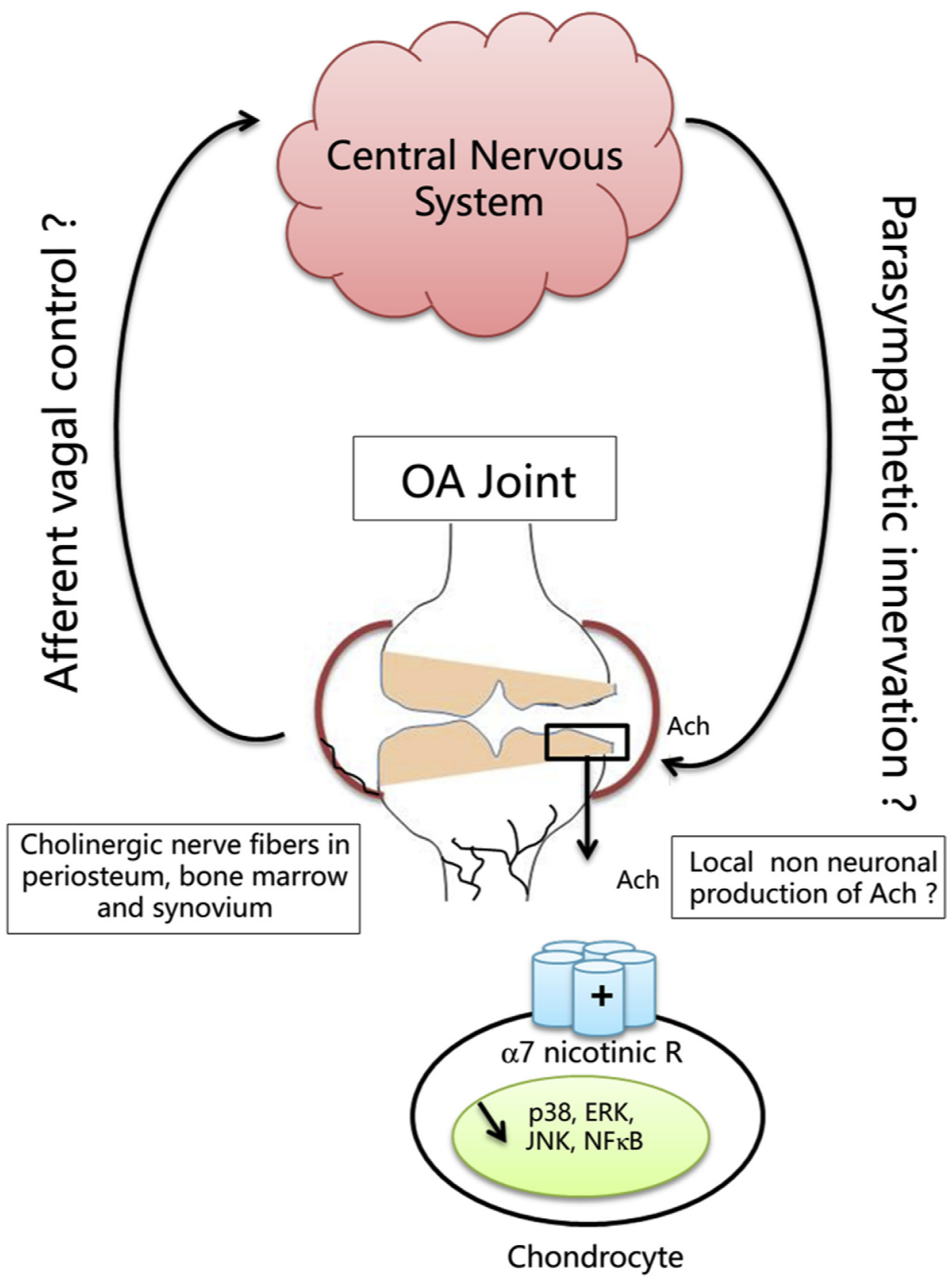

Fig. 2. Hypothetical action of the PNS and cholinergic fibers in osteoarthritis. Parasympathetic innervation of the joint tissue is possible, especially in the bone (Bajayo et al., 2012). Parasympathetic fibers may have a role in the control of local inflammation because the vagus nerve and acetylcholine (Ach) have demonstrated a strong anti-inflammatory potential through their action on a specific nicotinic receptor, alpha-7. Furthermore, PNS fibers could have an anti-inflammatory role through an afferent feedback on the central nervous system (on the hypothalamo- pituitary axis). Beyond PNS innervation, cholinergic fibers have been demonstrated in the periosteum, bone marrow, and synovium. The locally produced Ach may act on receptors expressed by local resident cells such as synoviocytes or chondrocytes. Thus, chondrocytes express the alpha-7 receptor nicotinic receptor ( $\alpha 7$ nicotinic $R$ ), which when activated has an antiinflammatory role on the phosphorylation of p38 extracellular signal-regulated kinase (ERK) 1/2 and c-Jun-N-terminal kinase (JNK) mitogen-activated protein kinases as well as nuclear factor-kappa $\mathrm{B}(\mathrm{NF} \kappa \mathrm{B}) \mathrm{p} 65$. This may be a therapeutic pathway. 
apoptosis through the nicotinic alpha- 2 receptor and a converse proliferative effect on osteoblasts up to a certain dose [47], with no effect on the production of alkaline phosphatase, RANK-L, or Osterix, which suggests that cholinergic agonists regulate the number of osteoblasts rather than their differentiation or activity. This action of the PNS on bone mass is under the action of IL-1 produced by the central nervous system. Similarly, the M3 muscarinic receptor appears to play a positive role in bone mass because knockout mice show decreased bone mass $[84,85]$. Alpha- 7 nicotinic receptor, probably the most promising for low-grade inflammation, has a small role in bone mass, but the effect is rather negative and indirect [86,87]. Hence, the evaluation of specific agonists or osteoclasts in mice with knockout of the alpha-7 nicotinic subunit did not show any particular differences. However, vagal nerve stimulation inhibited TNF production through the macrophage alpha-7 receptor, which was responsible for a decrease in serum osteoprotegerin-toRANK-L ratio and thus osteoclast activation [87]. Therefore, the effect of vagus nerve stimulation on bone remodeling biomarkers should be investigated.

\section{Summary}

Many resident cells of the osteoarticular system express receptors for sympathetic and parasympathetic neurotransmitters, which allow them to respond to autonomic stimuli. Sympathetic fibers innervate the synovium and bone and are important neuronal effectors of bone physiology. They are involved in bone mechanoadaptation and remodeling through the beta- 2 receptor. In the subchondral bone, SNS stimulates bone resorption by the activation of osteoclasts through RANK-L. Conversely, the involvement of SNS in synovitis and cartilage degradation is not clear and needs further investigation because of conflicting results (Table 1). Parasympathetic fibers also demonstrated a powerful antiinflammatory action mediated by the vagus nerve, its acetylcholine release, and the alpha-7 nicotinic receptor. However, this pathway has been demonstrated in highly inflammatory states such as RA or inflammatory bowel disease by systemic mechanisms involving the spleen. Furthermore, we still do not know whether parasympathetic fibers really innervate joint tissue, which is an essential issue to decipher the PNS involvement in OA (Fig. 2). Nevertheless, cholinergic fibers from sympathetic nerves innervate the periosteum and synovium. The non-neuronal cholinergic system is expressed by osteoarticular tissues, which possibly allow for local acetylcholine production regardless of innervation. Promising results of activation of the alpha-7 nicotinic receptor in OA models are needed. Finally, the SNS-PNS balance in OA needs to be studied because it may explain the association between hypertension and $\mathrm{OA}$.

\section{Research agenda}

- Evaluate the clinical balance of SNS and PNS in OA

- Determine precisely, using innovative methods, the innervation of joint tissues and especially the presence of cholinergic and parasympathetic fibers in joint tissues

- Determine whether parasympathetic fibers invade the osteochondral junction during OA

- Evaluate the impact of beta-blocker treatment on OA incidence, severity, and progression in prospective cohorts

- Determine the impact of sympathectomy on OA severity in a murine model

- Determine the involvement of adrenergic, nicotinic, or muscarinic receptors in $O A$ in knockout mice

- Determine the impact of vagus nerve stimulation and/or vagotomy on OA in a murine model of OA

- Determine whether ANS is involved in the association between hypertension and OA 


\section{Practice points}

- Sympathetic fibers innervate healthy and OA synovial and bone tissues. Their density decreased in areas of high synovial inflammatory activity, although the involvement of these fibers in OA-related inflammation remains controversial. During OA, sprouting of sympathetic fibers is observed in the subchondral bone, and their activation is related to an increased bone resorption/bone loss through beta- 2 receptors. However, to date, there are no therapeutic options of specific sympathetic blockade available for OA.

- Early studies have found cholinergic fibers in the bone tissue. Their impact on joint homeostasis remains unknown. However, alpha-7 nicotinic receptor activation has demonstrated strong anti-inflammatory properties on macrophages and possibly on chrondrocytes, which provides scope in this field of research in OA. We still need further studies to better understand the involvement of cholinergic transmitters in OA pathophysiology.

\section{Funding source}

The authors received no specific funding for this work.

\section{Conflict of interest statement}

The authors have no conflict of interest related to this work.

\section{References}

[1] Bijlsma JWJ, Berenbaum F, Lafeber FPJG. Osteoarthritis: an update with relevance for clinical practice. Lancet 2011;377: 2115-26. https://doi.org/10.1016/S0140-6736(11)60243-2.

[2] Courties A, Sellam J, Berenbaum F. Metabolic syndrome-associated osteoarthritis. Curr Opin Rheumatol 2017;29:214-22. https://doi.org/10.1097/BOR.0000000000000373.

[3] Hukkanen M, Konttinen YT, Rees RG, Santavirta S, Terenghi G, Polak JM. Distribution of nerve endings and sensory neuropeptides in rat synovium, meniscus and bone. Int J Tissue React 1992;14:1-10.

[4] Halata Z, Rettig T, Schulze W. The ultrastructure of sensory nerve endings in the human knee joint capsule. Anat Embryol 1985; 172:265-75.

[5] Saito T, Koshino T. Distribution of neuropeptides in synovium of the knee with osteoarthritis. Clin Orthop Relat Res 2000: $172-82$.

[6] Oliva F, Tarantino U, Maffulli N. Immunohistochemical localization of calcitonin gene-related peptide and substance P in the rat knee cartilage at birth. Physiol Res 2005;54:549-56.

[7] Niedermair T, Kuhn V, Doranehgard F, Stange R, Wieskötter B, Beckmann J, et al. Absence of substance P and the sympathetic nervous system impact on bone structure and chondrocyte differentiation in an adult model of endochondral ossification. Matrix Biol 2014;38:22-35. https://doi.org/10.1016/j.matbio.2014.06.007.

[8] Gajda M, Adriaensen D, Cichocki T. Development of the innervation of long bones: expression of the growth-associated protein 43. Folia Histochem Cytobiol 2000;38:103-10.

[9] Huebner AK, Keller J, Catala-Lehnen P, Perkovic S, Streichert T, Emeson RB, et al. The role of calcitonin and alphacalcitonin gene-related peptide in bone formation. Arch Biochem Biophys 2008;473:210-7. https://doi.org/10.1016/j. abb.2008.02.013.

[10] Im H-J, Li X, Muddasani P, Kim G-H, Davis F, Rangan J, et al. Basic fibroblast growth factor accelerates matrix degradation via a neuro-endocrine pathway in human adult articular chondrocytes. J Cell Physiol 2008;215:452-63. https://doi.org/ 10.1002/jcp.21317.

*[11] Eitner A, Pester J, Nietzsche S, Hofmann GO, Schaible H-G. The innervation of synovium of human osteoarthritic joints in comparison with normal rat and sheep synovium. Osteoarthritis Cartilage 2013;21:1383-91. https://doi.org/10.1016/j. joca.2013.06.018.

[12] Miller LE, Jüsten HP, Schölmerich J, Straub RH. The loss of sympathetic nerve fibers in the synovial tissue of patients with rheumatoid arthritis is accompanied by increased norepinephrine release from synovial macrophages. Faseb J 2000;14: 2097-107. https://doi.org/10.1096/fj.99-1082com.

[13] Mach DB, Rogers SD, Sabino MC, Luger NM, Schwei MJ, Pomonis JD, et al. Origins of skeletal pain: sensory and sympathetic innervation of the mouse femur. Neuroscience 2002;113:155-66.

[14] Lorenz J, Schäfer N, Bauer R, Jenei-Lanzl Z, Springorum RH, Grässel S. Norepinephrine modulates osteoarthritic chondrocyte metabolism and inflammatory responses. Osteoarthritis Cartilage 2015. https://doi.org/10.1016/j.joca.2015.08.007.

*[15] Borovikova LV, Ivanova S, Zhang M, Yang H, Botchkina GI, Watkins LR, et al. Vagus nerve stimulation attenuates the systemic inflammatory response to endotoxin. Nature 2000;405:458-62. https://doi.org/10.1038/35013070.

[16] Forsgren S. Presence of ChAT mRNA and a very marked $\alpha 7 \mathrm{nAChR}$ immunoreaction in the synovial lining layer of the knee joint. Life Sci 2012;91:1043-7. https://doi.org/10.1016/j.lfs.2012.03.028. 
[17] Schubert J, Beckmann J, Hartmann S, Morhenn H-G, Szalay G, Heiss C, et al. Expression of the non-neuronal cholinergic system in human knee synovial tissue from patients with rheumatoid arthritis and osteoarthritis. Life Sci 2012;91: 1048-52. https://doi.org/10.1016/j.lfs.2012.04.032.

*[18] Suri S, Gill SE, Massena de Camin S, Wilson D, McWilliams DF, Walsh DA. Neurovascular invasion at the osteochondral junction and in osteophytes in osteoarthritis. Ann Rheum Dis 2007;66:1423-8. https://doi.org/10.1136/ard.2006. 063354.

[19] Sellam J, Berenbaum F. The role of synovitis in pathophysiology and clinical symptoms of osteoarthritis. Nat Rev Rheumatol 2010;6:625-35. https://doi.org/10.1038/nrrheum.2010.159.

[20] Buma P, Verschuren C, Versleyen D, Van der Kraan P, Oestreicher AB. Calcitonin gene-related peptide, substance P and GAP-43/B-50 immunoreactivity in the normal and arthrotic knee joint of the mouse. Histochemistry 1992;98:327-39.

[21] Murakami K, Nakagawa H, Nishimura K, Matsuo S. Changes in peptidergic fiber density in the synovium of mice with collagenase-induced acute arthritis. Can J Physiol Pharmacol 2015;93:435-41. https://doi.org/10.1139/cjpp-2014-0446.

[22] Grönblad M, Konttinen YT, Korkala O, Liesi P, Hukkanen M, Polak JM. Neuropeptides in synovium of patients with rheumatoid arthritis and osteoarthritis. J Rheumatol 1988;15:1807-10.

[23] Saxler G, Löer F, Skumavc M, Pförtner J, Hanesch U. Localization of SP- and CGRP-immunopositive nerve fibers in the hip joint of patients with painful osteoarthritis and of patients with painless failed total hip arthroplasties. Eur J Pain 2007; 11:67-74. https://doi.org/10.1016/j.ejpain.2005.12.011.

[24] Walsh DA, Bonnet CS, Turner EL, Wilson D, Situ M, McWilliams DF. Angiogenesis in the synovium and at the osteochondral junction in osteoarthritis. Osteoarthritis Cartilage 2007;15:743-51. https://doi.org/10.1016/j.joca.2007.01.020.

[25] Burr DB, Gallant MA. Bone remodelling in osteoarthritis. Nat Rev Rheumatol 2012;8:665-73. https://doi.org/10.1038/ nrrheum.2012.130.

[26] Koopman FA, Schuurman PR, Vervoordeldonk MJ, Tak PP. Vagus nerve stimulation: a new bioelectronics approach to treat rheumatoid arthritis? Best Pract Res Clin Rheumatol 2014;28:625-35. https://doi.org/10.1016/j.berh.2014.10.015.

[27] Koopman FA, Chavan SS, Miljko S, Grazio S, Sokolovic S, Schuurman PR, et al. Vagus nerve stimulation inhibits cytokine production and attenuates disease severity in rheumatoid arthritis. Proc Natl Acad Sci USA 2016;113:8284-9. https://doi. org/10.1073/pnas.1605635113.

[28] Koopman FA, van Maanen MA, Vervoordeldonk MJ, Tak PP. Balancing the autonomic nervous system to reduce inflammation in rheumatoid arthritis. J Intern Med 2017;282:64-75. https://doi.org/10.1111/joim.12626.

[29] Bonaz B, Sinniger V, Pellissier S. Vagus nerve stimulation: a new promising therapeutic tool in inflammatory bowel disease. J Intern Med 2017;282:46-63. https://doi.org/10.1111/joim.12611.

[30] Olofsson PS, Katz DA, Rosas-Ballina M, Levine YA, Ochani M, Valdés-Ferrer SI, et al. $\alpha 7$ nicotinic acetylcholine receptor $(\alpha 7 \mathrm{nAChR})$ expression in bone marrow-derived non-T cells is required for the inflammatory reflex. Mol Med 2012;18: 539-43. https://doi.org/10.2119/molmed.2011.00405.

[31] Rosas-Ballina M, Ochani M, Parrish WR, Ochani K, Harris YT, Huston JM, et al. Splenic nerve is required for cholinergic antiinflammatory pathway control of TNF in endotoxemia. Proc Natl Acad Sci USA 2008;105:11008-13. https://doi.org/ 10.1073/pnas.0803237105.

*[32] Rosas-Ballina M, Olofsson PS, Ochani M, Valdés-Ferrer SI, Levine YA, Reardon C, et al. Acetylcholine-synthesizing T cells relay neural signals in a vagus nerve circuit. Science 2011;334:98-101. https://doi.org/10.1126/science.1209985.

[33] de Jonge WJ, van der Zanden EP, The FO, Bijlsma MF, van Westerloo DJ, Bennink RJ, et al. Stimulation of the vagus nerve attenuates macrophage activation by activating the Jak2-STAT3 signaling pathway. Nat Immunol 2005;6:844-51. https:// doi.org/10.1038/ni1229.

[34] Yoshikawa H, Kurokawa M, Ozaki N, Nara K, Atou K, Takada E, et al. Nicotine inhibits the production of proinflammatory mediators in human monocytes by suppression of I-kappaB phosphorylation and nuclear factor-kappaB transcriptional activity through nicotinic acetylcholine receptor alpha7. Clin Exp Immunol 2006;146:116-23. https://doi.org/10.1111/j. 1365-2249.2006.03169.x.

[35] Zygmunt A, Stanczyk J. Methods of evaluation of autonomic nervous system function. Arch Med Sci 2010;6:11-8. https:// doi.org/10.5114/aoms.2010.13500.

[36] Evrengül H, Dursunoglu D, Cobankara V, Polat B, Seleci D, Kabukçu S, et al. Heart rate variability in patients with rheumatoid arthritis. Rheumatol Int 2004;24:198-202. https://doi.org/10.1007/s00296-003-0357-5.

[37] Provan SA, Olstad DS, Solberg EE, Smedslund G, Dagfinrud H. Evidence of reduced parasympathetic autonomic regulation in inflammatory joint disease: a meta-analyses study. Semin Arthritis Rheum 2017. https://doi.org/10.1016/j.semarthrit. 2017.11.010.

[38] Miller LE, Weidler C, Falk W, Angele P, Schaumburger J, Schölmerich J, et al. Increased prevalence of semaphorin 3C, a repellent of sympathetic nerve fibers, in the synovial tissue of patients with rheumatoid arthritis. Arthritis Rheum 2004 50:1156-63. https://doi.org/10.1002/art.20110.

[39] Tabarowski Z, Gibson-Berry K, Felten SY. Noradrenergic and peptidergic innervation of the mouse femur bone marrow. Acta Histochem 1996;98:453-7. https://doi.org/10.1016/S0065-1281(96)80013-4.

*[40] Artico M, Bosco S, Cavallotti C, Agostinelli E, Giuliani-Piccari G, Sciorio S, et al. Noradrenergic and cholinergic innervation of the bone marrow. Int J Mol Med 2002;10:77-80.

[41] Beckmann J, Knödl M, Bauser E, Tingart M, Grifka J, Straub RH. Loss of sympathetic nerve fibers in vital intertrochanteric bone cylinders lateral to osteonecrosis of the femoral head. Joint Bone Spine 2013;80:188-94. https://doi.org/10.1016/j. jbspin.2012.03.003.

[42] Koeck F-X, Bobrik V, Fassold A, Grifka J, Kessler S, Straub RH. Marked loss of sympathetic nerve fibers in chronic Charcot foot of diabetic origin compared to ankle joint osteoarthritis. J Orthop Res 2009;27:736-41. https://doi.org/10.1002/jor. 20807.

[43] Jiao K, Niu L-N, Li Q, Ren G, Zhao C, Liu Y, et al. $\beta 2$-Adrenergic signal transduction plays a detrimental role in subchondral bone loss of temporomandibular joint in osteoarthritis. Sci Rep 2015;5:12593. https://doi.org/10.1038/srep12593.

[44] Lehner B, Koeck FX, Capellino S, Schubert TEO, Hofbauer R, Straub RH. Preponderance of sensory versus sympathetic nerve fibers and increased cellularity in the infrapatellar fat pad in anterior knee pain patients after primary arthroplasty. J Orthop Res 2008;26:342-50. https://doi.org/10.1002/jor.20498. 
[45] Asmus SE, Parsons S, Landis SC. Developmental changes in the transmitter properties of sympathetic neurons that innervate the periosteum. J Neurosci 2000;20:1495-504.

[46] Stangl H, Springorum H-R, Muschter D, Grässel S, Straub RH. Catecholaminergic-to-cholinergic transition of sympathetic nerve fibers is stimulated under healthy but not under inflammatory arthritic conditions. Brain Behav Immun 2015;46: 180-91. https://doi.org/10.1016/j.bbi.2015.02.022.

*[47] Bajayo A, Bar A, Denes A, Bachar M, Kram V, Attar-Namdar M, et al. Skeletal parasympathetic innervation communicates central IL-1 signals regulating bone mass accrual. Proc Natl Acad Sci USA 2012;109:15455-60. https://doi.org/10.1073/ pnas.1206061109.

[48] Lilly GD. Effect of sympathectomy on development of chronic osteoarthritis: case report. Ann Surg 1966;163:856-8.

[49] Ebbinghaus M, Gajda M, Boettger MK, Schaible H-G, Bräuer R. The anti-inflammatory effects of sympathectomy in murine antigen-induced arthritis are associated with a reduction of Th1 and Th17 responses. Ann Rheum Dis 2012;71:253-61. https://doi.org/10.1136/ard.2011.150318.

[50] Härle P, Möbius D, Carr DJJ, Schölmerich J, Straub RH. An opposing time-dependent immune-modulating effect of the sympathetic nervous system conferred by altering the cytokine profile in the local lymph nodes and spleen of mice with type II collagen-induced arthritis. Arthritis Rheum 2005;52:1305-13. https://doi.org/10.1002/art.20987.

[51] Klatt S, Stangl H, Kunath J, Lowin T, Pongratz G, Straub RH. Peripheral elimination of the sympathetic nervous system stimulates immunocyte retention in lymph nodes and ameliorates collagen type II arthritis. Brain Behav Immun 2016;54: 201-10. https://doi.org/10.1016/j.bbi.2016.02.006.

[52] Pongratz G, Straub RH. The sympathetic nervous response in inflammation. Arthritis Res Ther 2014;16:504.

[53] Zhang Y-M, Wang J, Liu X-G. Association between hypertension and risk of knee osteoarthritis: a meta-analysis of observational studies. Medicine (Baltim) 2017;96:e7584. https://doi.org/10.1097/MD.0000000000007584.

[54] Valdes AM, Abhishek A, Muir K, Zhang W, Maciewicz RA, Doherty M. Association of beta-blocker use with less prevalent joint pain and lower opioid Requirement in people with osteoarthritis. Arthritis Care Res 2017;69:1076-81. https://doi. org/10.1002/acr.23091.

[55] Martin LJ, Piltonen MH, Gauthier J, Convertino M, Acland EL, Dokholyan NV, et al. Differences in the antinociceptive effects and binding properties of propranolol and bupranolol enantiomers. J Pain 2015;16:1321-33. https://doi.org/10. 1016/j.jpain.2015.09.004.

[56] Driban JB, Lo GH, Eaton CB, Lapane KL, Nevitt M, Harvey WF, et al. Exploratory analysis of osteoarthritis progression among medication users: data from the Osteoarthritis Initiative. Ther Adv Musculoskelet Dis 2016;8:207-19. https://doi org/10.1177/1759720X16664323.

[57] Jenei-Lanzl Z, Grässel S, Pongratz G, Kees F, Miosge N, Angele P, et al. Norepinephrine inhibition of mesenchymal stem cell and chondrogenic progenitor cell chondrogenesis and acceleration of chondrogenic hypertrophy. Arthritis Rheumatology (Hoboken NJ) 2014;66:2472-81. https://doi.org/10.1002/art.38695.

[58] Jenei-Lanzl Z, Zwingenberg J, Lowin T, Anders S, Straub RH. Proinflammatory receptor switch from Gas to Gai signaling by $\beta$-arrestin-mediated PDE4 recruitment in mixed RA synovial cells. Brain Behav Immun 2015;50:266-74. https://doi.org/ 10.1016/j.bbi.2015.07.020.

[59] Miller LE, Grifka J, Schölmerich J, Straub RH. Norepinephrine from synovial tyrosine hydroxylase positive cells is a strong indicator of synovial inflammation in rheumatoid arthritis. J Rheumatol 2002;29:427-35.

[60] Raap T, Jüsten HP, Miller LE, Cutolo M, Schölmerich J, Straub RH. Neurotransmitter modulation of interleukin 6 (IL-6) and IL-8 secretion of synovial fibroblasts in patients with rheumatoid arthritis compared to osteoarthritis. J Rheumatol 2000 27:2558-65.

[61] Takarada T, Hojo H, Iemata M, Sahara K, Kodama A, Nakamura N, et al. Interference by adrenaline with chondrogenic differentiation through suppression of gene transactivation mediated by Sox9 family members. Bone 2009;45:568-78. https://doi.org/10.1016/j.bone.2009.05.004.

[62] Lai LP, Mitchell J. Beta2-adrenergic receptors expressed on murine chondrocytes stimulate cellular growth and inhibit the expression of Indian hedgehog and collagen type X. J Cell Biochem 2008;104:545-53. https://doi.org/10.1002/jcb.21646.

[63] Tonge DP, Jones SW, Parr T, Bardsley R, Doherty M, Maciewicz RA. Beta2-adrenergic agonist-induced hypertrophy of the quadriceps skeletal muscle does not modulate disease severity in the rodent meniscectomy model of osteoarthritis Osteoarthritis Cartilage 2010;18:555-62. https://doi.org/10.1016/j.joca.2009.11.014.

[64] Jiao K, Zeng G, Niu L-N, Yang H-X, Ren G-T, Xu X-Y, et al. Activation of $\alpha 2 A$-adrenergic signal transduction in chondrocytes promotes degenerative remodelling of temporomandibular joint. Sci Rep 2016;6:30085. https://doi.org/10.1038/srep30085.

*[65] Elefteriou F, Ahn JD, Takeda S, Starbuck M, Yang X, Liu X, et al. Leptin regulation of bone resorption by the sympathetic nervous system and CART. Nature 2005;434:514-20. https://doi.org/10.1038/nature03398.

[66] Aitken SJ, Landao-Bassonga E, Ralston SH, Idris AI. Beta2-adrenoreceptor ligands regulate osteoclast differentiation in vitro by direct and indirect mechanisms. Arch Biochem Biophys 2009;482:96-103. https://doi.org/10.1016/j.abb.2008 11.012 .

[67] Arai M, Nagasawa T, Koshihara Y, Yamamoto S, Togari A. Effects of beta-adrenergic agonists on bone-resorbing activity in human osteoclast-like cells. Biochim Biophys Acta 2003;1640:137-42.

[68] Levasseur R, Sabatier J-P, Potrel-Burgot C, Lecoq B, Creveuil C, Marcelli C. Sympathetic nervous system as transmitter of mechanical loading in bone. Joint Bone Spine 2003;70:515-9.

[69] Kondo H, Nifuji A, Takeda S, Ezura Y, Rittling SR, Denhardt DT, et al. Unloading induces osteoblastic cell suppression and osteoclastic cell activation to lead to bone loss via sympathetic nervous system. J Biol Chem 2005;280:30192-200. https://doi.org/10.1074/jbc.M504179200.

[70] Huang HH, Brennan TC, Muir MM, Mason RS. Functional alpha1- and beta2-adrenergic receptors in human osteoblasts J Cell Physiol 2009;220:267-75. https://doi.org/10.1002/jcp.21761.

[71] Mlakar V, Jurkovic Mlakar S, Zupan J, Komadina R, Prezelj J, Marc J. ADRA2A is involved in neuro-endocrine regulation of bone resorption. J Cell Mol Med 2015;19:1520-9. https://doi.org/10.1111/jcmm.12505.

*[72] Grimsholm O, Rantapää-Dahlqvist S, Dalén T, Forsgren S. Unexpected finding of a marked non-neuronal cholinergic system in human knee joint synovial tissue. Neurosci Lett 2008;442:128-33. https://doi.org/10.1016/j.neulet.2008.06. 082 . 
[73] Westman M, Engström M, Catrina AI, Lampa J. Cell specific synovial expression of nicotinic alpha 7 acetylcholine receptor in rheumatoid arthritis and psoriatic arthritis. Scand J Immunol 2009;70:136-40. https://doi.org/10.1111/j.1365-3083. 2009.02266.x.

[74] Waldburger J-M, Boyle DL, Pavlov VA, Tracey KJ, Firestein GS. Acetylcholine regulation of synoviocyte cytokine expression by the alpha7 nicotinic receptor. Arthritis Rheum 2008;58:3439-49. https://doi.org/10.1002/art.23987.

[75] Beckmann J, Schubert J, Morhenn H-G, Grau V, Schnettler R, Lips KS. Expression of choline and acetylcholine transporters in synovial tissue and cartilage of patients with rheumatoid arthritis and osteoarthritis. Cell Tissue Res 2015;359:465-77. https://doi.org/10.1007/s00441-014-2036-0.

[76] van Maanen MA, Stoof SP, van der Zanden EP, de Jonge WJ, Janssen RA, Fischer DF, et al. The alpha7 nicotinic acetylcholine receptor on fibroblast-like synoviocytes and in synovial tissue from rheumatoid arthritis patients: a possible role for a key neurotransmitter in synovial inflammation. Arthritis Rheum 2009;60:1272-81. https://doi.org/10.1002/art.24470.

*[77] Kawakita A, Sato K, Makino H, Ikegami H, Takayama S, Toyama Y, et al. Nicotine acts on growth plate chondrocytes to delay skeletal growth through the alpha7 neuronal nicotinic acetylcholine receptor. PLoS One 2008;3:e3945. https://doi. org/10.1371/journal.pone.0003945.

[78] Ying X, Cheng S, Shen Y, Cheng X, An Rompis F, Wang W, et al. Nicotine promotes proliferation and collagen synthesis of chondrocytes isolated from normal human and osteoarthritis patients. Mol Cell Biochem 2012;359:263-9. https://doi. org/10.1007/s11010-011-1020-1.

*[79] Liu Y, Wu D, Song F, Zhu C, Hui Y, Zhu Q et al. Activation of $\alpha 7$ nicotinic acetylcholine receptors prevents monosodium iodoacetate-induced osteoarthritis in rats. Cell Physiol Biochem 2015;35:627-38. https://doi.org/10.1159/000369724.

[80] Bock K, Plaass C, Coger V, Peck C-T, Reimers K, Stukenborg-Colsman C, et al. What is the effect of nicotinic acetylcholine receptor stimulation on osteoarthritis in a rodent animal model? SAGE Open Med 2016;4. https://doi.org/10.1177/ 2050312116637529. 2050312116637529.

[81] Kong L, Wang L, Meng F, Cao J, Shen Y. Association between smoking and risk of knee osteoarthritis: a systematic review and meta-analysis. Osteoarthritis Cartilage 2017;25:809-16. https://doi.org/10.1016/j.joca.2016.12.020.

[82] Blagojevic M, Jinks C, Jeffery A, Jordan KP. Risk factors for onset of osteoarthritis of the knee in older adults: a systematic review and meta-analysis. Osteoarthritis Cartilage 2010;18:24-33. https://doi.org/10.1016/j.joca.2009.08.010.

[83] Lourido L, Calamia V, Fernández-Puente P, Mateos J, Oreiro N, Blanco FJ, et al. Secretome analysis of human articular chondrocytes unravels catabolic effects of nicotine on the joint. Proteonomics Clin Appl 2016;10:671-80. https://doi.org/ $10.1002 /$ prca.201400186.

[84] Kliemann K, Kneffel M, Bergen I, Kampschulte M, Langheinrich AC, Dürselen L, et al. Quantitative analyses of bone composition in acetylcholine receptor M3R and alpha7 knockout mice. Life Sci 2012;91:997-1002. https://doi.org/10. 1016/j.lfs.2012.07.024.

[85] Shi Y, Oury F, Yadav VK, Wess J, Liu XS, Guo XE, et al. Signaling through the M(3) muscarinic receptor favors bone mass accrual by decreasing sympathetic activity. Cell Metabol 2010;11:231-8. https://doi.org/10.1016/j.cmet.2010.01.005.

[86] Lips KS, Yanko Ö, Kneffel M, Panzer I, Kauschke V, Madzharova M, et al. Small changes in bone structure of female $\alpha 7$ nicotinic acetylcholine receptor knockout mice. BMC Musculoskelet Disord 2015;16:5. https://doi.org/10.1186/s12891015-0459-8.

[87] Mito K, Sato Y, Kobayashi T, Miyamoto K, Nitta E, Iwama A, et al. The nicotinic acetylcholine receptor $\alpha 7$ subunit is an essential negative regulator of bone mass. Sci Rep 2017;7:45597. https://doi.org/10.1038/srep45597. 